\title{
Evaluación de la elución de sensidiscos para la determinación de susceptibilidad a colistín en bacilos gramnegativos multi-resistentes
}

\author{
Evaluation of sensi-disk elution for colistin susceptibility determination in multidrug resistant \\ gramnegative bacilli
}

Matías Jofré ${ }^{1}$, Boris Barrera², Francisco Silva ${ }^{2}$ y Liliana Berrocal ${ }^{1}$

Laboratorio de Microbiología Molecular, Facultad de Medicina y Facultad de Odontología, Universidad Finis Terrae.
${ }^{2}$ Laboratorio Clínico, Unidad de Microbiología, Hospital Clínico de la Universidad de Chile.

Financiamiento: Proyecto CAI Dra. Liliana Berrocal, financiado por la Dirección de Investigación, Postítulo y Publicaciones de la Universidad Finis Terrae. Conflicto de Intereses: Ninguno.

Recibido: 3 de agosto de 2019 / Aceptado: 14 de enero de 2020

\section{Resumen}

Utilizando cepas clínicas de bacilos gramnegativos multi-resistentes (MDR), comparamos las CIM obtenidas de la microdilución en caldo, el método de referencia y el método de elución de sensidiscos. Encontramos que, con la excepción de A. baumannii, los resultados fueron muy similares. El método de elución de sensidiscos podría ser una buena alternativa y confiable para la determinación de la resistencia a colistín.

Palabras clave: Resistencia a colistín; microdilución en caldo; elución de sensidiscos; multi-resistencia a antibióticos.

\section{Introducción}

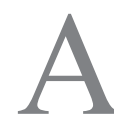
ctualmente, el aumento de infecciones causadas por bacilos gramnegativos multi-resistentes ha incrementado el uso de colistín como última alternativa terapéutica ${ }^{1}$. El método de referencia para determinar la susceptibilidad a este antimicrobiano es la microdilución en caldo; sin embargo, resulta costosa y poco práctica en los laboratorios clínicos. Por otro lado, los sistemas automatizados, la difusión en agar y los test de gradientes han mostrado una falsa susceptibilidad producto de las características químicas del colistín $n^{2,3}$. De modo que se requiere con urgencia estandarizar una metodología alternativa, confiable y factible de implementar como técnica de rutina.

Esta comunicación tiene como objetivo informar acerca del uso del método de elución de sensidiscos ${ }^{4}$, como alternativa para la determinación de susceptibilidad a colistín en bacilos gramnegativos multi-resistentes de relevancia clínica.

\begin{abstract}
Using clinical strains of multidrug resistant (MDR) Gram negative bacilli, we compared MICs obtained from both broth microdilution, the reference method, and sensi-disk elution method. We found that, with $A$. baumannii exception, results were very similar. Sensi-disk elution method could be a good and reliable alternative for colistin resistance determination.

Keywords: Colistin-resistance; broth microdilution; sensi-disk elution; multidrug resistance.
\end{abstract}

\section{Metodología}

Se les determinó susceptibilidad a colistín a 48 cepas de bacilos gramnegativos multi-resistentes (MDR) ${ }^{5}$ provenientes de pacientes internados del Hospital Clínico de la Universidad de Chile, mediante el método de elución de sensidiscos, y se comparó con la microdilución en caldo (método in house) tal como se ha reportado con anterioridad ${ }^{6}$, utilizando los puntos de corte indicados por CLSI $2018^{7}$.

Para la elución de sensidiscos, nos basamos en la metodología descrita por el Laboratorio de Medicina de la UCLA, California, E.U.A. ${ }^{4}$.

\section{Resultados}

De 48 cepas analizadas (43 enterobacterias, tres Pseudomonas aeruginosa, dos Acinetobacter baumannii), mediante el método de elución de

\footnotetext{
Correspondencia a:

Liliana Berrocal

lberrocal@uft.cl
} 
sensidiscos, se obtuvieron 42 susceptibles y cuatro resistentes, obteniendo 46 resultados coincidentes con el método de microdilución $(95,8 \%$ de concordancia categórica), con concentraciones inhibitorias mínimas (CIM) similares. Empleando la técnica de referencia, se obtuvieron 42 susceptibles y seis resistentes a colistín, de las cuales una correspondía a Enterobacter hormaechei (CIM $4 \mu \mathrm{g} / \mathrm{ml})$, una a Enterobacter cloacae (CIM > $16 \mu \mathrm{g} / \mathrm{ml})$, una a Serratia marcescens (CIM $>16 \mu \mathrm{g} / \mathrm{ml}$ ), una a Klebsiella pneumoniae $(\mathrm{CIM}>16 \mu \mathrm{g} / \mathrm{ml}$ ) y dos a $A$. baumannii (CIM $4 \mu \mathrm{g} / \mathrm{ml}$ ). Estas últimas fueron las cepas discordantes (falsas sensibles) que generaron un $4,2 \%$ de errores muy mayores, mientras que no hubo errores menores (puesto que no existe la categoría de sensibilidad intermedia para colistín) ni mayores (pues no hay falsas resistentes). Se obtuvo un valor de sensibilidad para la detección de susceptibilidad y resistencia de $100 \%$ cuando se excluyeron estas dos cepas de A. baumannii y de $67 \%$ con el total. Por otra parte, la especificidad obtenida para este mismo fin fue de $100 \%$ en todos los casos.

\section{Discusión}

La elución de sensidiscos resultó ser confiable para la determinación de susceptibilidad a colistín en bacilos gramnegativos de la familia Enterobacteriaceae y Pseudomonas, ya que mostró una elevada sensibilidad y especificidad tal como se ha reportado previamente para bacilos gramnegativos multi-resistentes ${ }^{4,10}$. Sin embargo, éste no fue concluyente para A. baumannii, lo que se relaciona con su falsa resistencia frente a colistín ${ }^{8}$ y con los errores muy mayores observados en nuestra investigación, por lo que se requiere hacer un estudio con un mayor número de cepas de este tipo. Cabe mencionar que hemos evaluado otros métodos de estudio como el Rapid Polymyxin NP 9 , pero este no es aconsejable ya que, a pesar de su elevada sensibilidad y rapidez, entrega una cantidad excesiva de falsos positivos (resultados no mostrados) y sólo se puede aplicar para Enterobacteriaceae.

Por otro lado, la elución de sensidiscos permite la obtención de una CIM aproximada, lo cual es particularmente útil a la hora de evaluar el régimen de dosis requeridas por el paciente. Además, se ha reportado que al suplementar el medio Mueller-Hinton ajustado a cationes con EDTA, se puede evaluar la resistencia a colistín mediada por plásmidos ${ }^{10}$, lo cual es relevante para la transferencia entre patógenos. También cabe destacar que tiene menor costo y es moderadamente laborioso en comparación al método de referencia, lo que posibilitaría su implementación en el diagnóstico clínico.

En conclusión, la técnica de elución es aconsejable para determinar la susceptibilidad a colistín de bacterias de la familia Enterobacteriaceae y Pseudomonas.

\section{Referencias bibliográficas}

1.- Aguayo A, Mella S, Riedel G, Bello H, Domínguez M, González-Rocha G. Colistín en la era post-antibiótica. Rev Chilena Infectol 2016; 33: 166-76. doi: 10.4067/S0716-10182016000200006.

2.- Poirel L, Jayol A, Nordmann P. Polymyxins: Antibacterial activity, susceptibility testing, and resistance mechanisms encoded by plasmids or chromosomes. Clin Microbiol Rev 2017; 30: 557-96. doi: 10.1128/ CMR.00064-16.

3.- Bakthavatchalam Y D, Pragasam A K, Biswas I, Veeraraghavan B. Polymyxin susceptibility testing, interpretative breakpoints and resistance mechanisms: An update. J Glob Antimicrob Resist 2018; 12: 124-36. doi: 10.1016/j.jgar.2017.09.011.

4.- Simner P J, Bergman Y, Trejo M, Roberts A A, Marayan R, Tekle T, et al. Two-site evaluation of the colistin broth disk elution test to determine colistin in vitro activity against gramm-negative bacilli. J Clin Microbiol 2019; 57: e01163-18. doi: 10.1128/JCM.01163-18.

5.- Jiménez Pearson M A, Galas M, Corso A, Hormazábal J C, Duarte Valderrama C, Salgado Marcano N, et al. Consenso latinoamericano para definir, categorizar y notificar patógenos multirresistentes, con resistencia extendida o panresistentes. Rev Panam Salud Publica 2019; 43:e65. doi:10.26633/RPSP.2019.65.

6.- Protocolo para determinación de Concentración Inhibitoria Mínima por el Método de Microdilución. Aplicación para determinar la sensibilidad a Colistín. Servicio Antimicrobianos, Laboratorio Nacional de Referencia en Antimicrobianos, INEI-ANLIS. “Dr. Carlos G. Malbrán”. Versión 1. Julio 2017. Disponible en: http://antimicrobianos.com.ar/ATB/wp-content/ uploads/2017/09/Protocolo-CIM-microdiluci\%C3\%B3n-COL-version2Agosto-2017.pdf.

7.- Clinical and Laboratory Standards Institute (CLSI). M100, 28th Edition, 2018. Performance Standards for Antimicrobial Susceptibility Testing. Disponible en: https://clsi.org/media/1930/m100ed28_sample.pdf.

8.- Villanueva X, Opazo-Capurro A, Quezada-Aguiluz M, Domínguez M, Bello-Toledo H, González-Rocha G. ¿Se debe revisar la determinación de la CIM de colistín en Acinetobacter baumannii? Rev Chilena Infectol 2017; 34: 413-4. doi: 10.4067/s0716-10182017000400413.

9.- Nordmann P, Jayol A, Poirel L. Rapid detection of polymyxin resistance in Enterobacteriaceae. Emerg Infect Dis 2016; 22: 1038-43. doi: 10.3201/ eid2206.151840.

10.- Bell DT, Bergman Y, Kazmi AQ, Lewis S, Tamma PD, Simner PJ, et al. A novel phenotypic method to screen for plasmid-mediated colistin resistance among Enterobacteriales. J Clin Microbiol 2019; 57: e00040-19. doi: 10.1128/JCM.00040-19. 